\title{
A Theoretical Perspective on factors that Influence the Perception of Generation $\mathrm{Z}$ towards Workplace
}

\author{
Dr.S. Brindha, HoD \&Associate Professor, GRD Institute of Management, Coimbatore \& India. \\ brindhas@gmail.com
}

SaranyaPriyadarshini.C, Ph.D Scholar, GRD Institute of Management, Coimbatore \& India.

priya_sars@yahoo.co.in

\begin{abstract}
Generation Z, mostly born after the year of 2000 on literature, also known as mobile generation are assumed to enter into Business in the nearing years. They grow up with technology a fortiori and together with world wide web, mp3 players, short message, cell phones, PDAs, YouTube, IPADs, media technologies. Their Character and mindsets are seen to be different when compared to previous generations. The generation $\mathbf{Z}$ who will participate or participated in the labor force recently, their expectations are different from other employees._Gen $Z$ is entrepreneurial, less motivated by money and more focused on face-to-face communication. This study is to determine the work perception factors of Generation Z.
\end{abstract}

Keywords: Generation Z, Mobile Generation, Independent, Teamwork, Technology, Work Perception.

\section{INTRODUCTION}

Until the last quarter of the 20th century, while the work was seen as the center of the life for individuals, together with the improving technology expectations of workers from the professional life became different. Changing professional life as well as individuals' changing perceptions and perspective on work made the generation concept a subject, which is needed to be surveyed more closely. Mostly seen on literature of sociology, this conception became an important topic that must be emphasized on business community and in a wide selection of fields. Taking place, the manager and workers of business community on different generations interests the business community intimately. Generation concept is defined a group that shares important vital events at the same birth year and critical developments within these events (Kupperschmidt, 2000: 66). Consuming habits and individually basic social values of every generation are formed with the effect of environment and values that surrounds it on growing period (Seckin, 2000: 101). Silent generation (1925-1944), Baby increment (1945-1964), Generation X (1965-1979), Generation Y (1980- 2000) (Cooman and Dries, 2012: 44). In the national and international literature, Generation $\mathrm{Z}$ born after the year 2000 , is self-confident, happy, fit to the team spirit and likes social service activities and also more interested in activities than the prior generations.

\section{OBJECTIVES}

- To understand the impact of Gen $\mathrm{Z}$ at workplace
- To identify the factors of Gen $\mathrm{Z}$ perception towards workplace

\section{LITERATURE REVIEW}

According to a study by (Wellner, 2000), Gen Zers give much importance to security. As the present world moves towards development and advancement, it provides open information regarding everything; they tend to be more aware and keep themselves secure.

In another study conducted by (Langford, 2008) Gen Zers prefer independence. According to a report on Entrepreneur India (2016), Gen $\mathrm{Z}$ employees prefer to work in a group as they are "Crowdsourcing". They wish the work to be accomplished by themselves rather than others interfering in the work. They prefer the internet for their work to be done.

Further studies by Kolnhofer-Derecskei and Reicher (2017), new ways have been created for communication. Gen $\mathrm{Z}$ makes proper use of technology for this purpose. They can gather information quickly; they adapt well to any situations and can multitask. They are available online most of the times surfing on the web during their free time.

According to a study by Patel (2017), Gen Zers, to a great extent see themselves as the business visionaries without any bounds. Indeed, even as internal employees, they have grasped - even longed for - a move toward greater adaptability. This interest for work-life stability will not just drive more representatives into the outsourcing domain, but also would move organization culture in ways that are advantageous to the organizations, consultants, and internal employees alike. Organizations need to stay aggressive and 
select talents of any age who would consider adopting to organizational culture and livens that interest to Gen $\mathrm{Z}$.

\section{GENERATION Z CHARACTERISTICS}

Generation $\mathrm{Z}$ is a group characterized by smartphones and social media. This generation values information ondemand and is leery of both authority figures and brands on social media. They can also be thought of as the "me me me" generation, accustomed to consuming vast amounts of information from many different platforms simultaneously. Gen $\mathrm{Z}$ uses social media to understand more about products before making purchases. Gen Z'ers, this generation wants to engage one-on-one with their organizational leaders. Management should be actively involved in the progression of their careers. Creating an effective strategy to allow this generation to receive mentorship, sponsorship, and also one-on-one guidance from leaders can be a beneficial approach to keeping this group engaged. Despite being a generation that is characterized by smart devices and Snapchat, Gen Z'ers also crave human connection in the workplace by giving the importance of their relationships with coworkers and supervisor interactions.

\section{IMPACT OF GEN Z AT WORKPLACE}

Organizations can reap the strengths of this generation in a few different ways. Because this generation is so tech savvy, they may pick up on some aspects of the job more quickly than their counterparts. On the other hand, because this generation is so used to communication via text and video, they may be ill-equipped for jobs requiring high customer interactions and may require more training in this area. Similar to their millennial counterparts, this generation also desires regular feedback about their performance. It is found that this generation desire daily interactions with their boss. As employees, Gen Z'ers want frequent interactions with supervisors and organizational leaders. They value regular feedback about their performance, and contrary to popular perceptions, this group values face-to-face interactions. In regard to training, this generation is very tech-savvy but may require a bit more assistance when it comes to customer-facing roles.

\section{PERCEPTION FACTORS OF GEN Z AT WORKPLACE}

As preferences of work and workplace are different for different generations, it is vital to understand the perceptions of the Gen $\mathrm{Z}$ so that the channel of communication is recognized, and good environment is created in the organization. It is also significant to understand what motivates them for the organizational throughput.

\section{Usage Towards Technology and Social Media}

Generation $\mathrm{Z}$ grew up during the most accelerated and game-changing periods of technological advancements in human history. Generation Z doesn't know a world where a smart device has been outside of arm's reach. Having 24/7 access to the world's information via a supercomputer in their pocket has rewired how Generation $\mathrm{Z}$ problem-solves, networks, communicates, learns, buys, and ultimately how they will show up in the workplace. Generation Z's top mobile activities include text messaging, downloading apps, playing preinstalled games and mobile internet/accessing websites and live video calling. They have their digital devices in bed in the evening. They list gaming as their main hobby. They are authentic story seekers, fearful of missing out (FOMO), and video centric. The top websites/apps used by Generation $\mathrm{Z}$ are YouTube, WhatsApp, Facebook, Gmail ,Snapchat, Instagram, Twitter and Facebook. They say social media affects self-esteem and think carefully about what they put on social media. Checks in on social media at least hourly. They spend more time refreshing their Twitter feed than even reading it.

\section{Cultural Acceptancy of Gen Z}

In recent years, businesses have modified the way they work in order to attract and retain millennials. Now, there's a new tech-savvy generation entering the workforce with their own needs and expectations. Generation $\mathrm{Z}$ consider themselves to be the hardest-working generation in the workforce. Gen $\mathrm{Z}$ workers described themselves as personally responsible for their own career, and they would be willing to work nights and weekends for higher pay. Gen Zers prefer structure and direction in their day-to-day roles. Though they may prefer to work remotely, or at least have the option, they also need to understand their roles, when tasks need to be completed and how their work impacts the business.

\section{Flexible Working}

Flexible working is a must, with the option to work remotely being a major plus point for Gen $\mathrm{Z}$ employees. The rise of "digital nomads" is a reflection of Gen Zers choosing alternative modes of working. For many businesses, this transition may be difficult, particularly for legacy businesses who still operate set working hours. Many businesses are already making the transition to a more flexible approach due to millennial demands, but to ensure a skilled talent pipeline for the future, HR departments within businesses may have to drive for more radical change.

\section{Multitasking}

Multitasking is also one of the positive generation $\mathrm{Z}$ traits. Due to their extraordinary ability to process and absorb lots of information within seconds, Gen Z kids can easily handle several tasks at once. They absorb tons of new information every day. Gen $\mathrm{Z}$ students listen to music, send text messages, watch TV, or use social media while doing their homework. Some studies revealed that doing something else together with the home assignments does not affect their productivity and in some cases even helps them become 
more productive. Besides, Gen Zers start earning their own money much earlier than the millennials used to, and thus the multitasking skills help them combine work and study.

\section{Independent}

Generation $\mathrm{Z}$ feel that the skills necessary in today's workforce are different from the skills necessary in past generations. For the generation that is younger than Google, they approach problem-solving and knowledge-sharing much differently than previous generations. They prefer a fully self-directed and independent approach to learning. They have also seen their millennial counterparts struggle to get on the career ladder. Because of this, Gen Zers are independent, hard-working, and willing to work to pay off their debts and achieve individual career success.

\section{Privacy}

Unlike the Millennial "Facebook" generation, the new generation is aware of risks associated with posting static content online where it can be stored and accessed by employers, friends or family for years. Gen $\mathrm{Z}$ prefers Snapchat or Whisper where conversations and images disappear after viewing, more like a face-to-face conversation, leaving no digital footprint.

\section{Teamwork}

Although Gen $\mathrm{Z}$ are always looking to further their skills and improve their own development, how does this relate to building a team? By performing individual tasks that contribute to a team initiative, Gen $\mathrm{Z}$ feel as though they are retaining their individuality, whilst still contributing towards something greater than themselves. This is unlike workers of the past, who would usually work together in less isolating environments so that a job was completed. In more horizontal forms of management, where responsibility is spread over a number of individuals, to become influential takes time and effort on the individual's behalf so that other workers can recognise the importance of their contributions. Strangely, although Gen $\mathrm{Z}$ are less team-orientated, they have a greater sense of work culture and their identity within it and their identity is linked to the work that they do every day. Gen $\mathrm{Z}$ feel as though they are retaining their individuality, as they can perform individual tasks that contribute towards a whole team cohort.

\section{CONCLUSION}

Every time a new generation enters the workforce, managers tend to struggle to understand the new group as it is assumed that generations differ and therefore understanding the different motives, attitudes and Perceptions is crucial for attracting and retaining talented workforce from a particular generation. Nowadays, a new generation is entering the world of work and thus attracts its attention.
As Generation $\mathrm{Z}$ enters the workforce, we will see a big change in the organization. With their unique skill sets, their culture of hard work, and their desire for cultural change, they may pose some challenges for businesses. Ultimately, however, they like millennials will change the world of work for the better. After all, improvements that benefit Gen Zers will also benefit everyone else. Gen Z seems to have different requirements and motivating factors than the earlier generations. This generation will be blending its own unique needs upon the workplace as they enter the organizations. It is important for the organization to realize what's important to the Gen $\mathrm{Z}$ before to boost attraction within and outside the industry in order to establish a corporate culture and workplace to gain a distinctive advantage in the hunt for top talent employees from the Generation $\mathrm{Z}$

\section{REFERENCES}

[1] Kapil Y., Roy, A. (2014), "Critical Evaluation of Generation Z at Workplaces", International Journal of Social Relevance\&Concern, Volume 2, Issue1, , p.1011., 10-14.

[2] Kupperschmidt B.R. (2000), "Multigeneration employees: Strategies for Effective Management", The Health Care Manager,19, p.66.,65-76.

[3] Rein De Cooman and Nicky Dries, 2012, “Attracting Generation Y: How Work Values Predict Organizational Attraction in Graduating Students in Belgium", Managing the New Workforce, UK, p.44., 44-63.

[4] Seckin S. F. (2000), Turkiye'nin Kusak Profili. Capital Journal (12), p. 101, 100-106.

[5] Mustafa Ozkana, Betul Solmazb (2015), "The Changing Face of The Employees- Generation Z And Their Perceptions Of Work", Procedia Economics and Finance, PP: 476 - 483.

[6] Dan Scawbel (2014), Millenial Brandin and Randstad US Release First Worldwide study comparing Gen Y and Gen Z Workplace expectations, Gen Y and Gen Z Global Workplace Expectations Study.

[7] Janice Gassam (2018), How Generation Z will impact your Workplace.

[8] Ryan Jenkins, How Generation Z Uses Technology and Social Media.

[9] Tom Brooks (2019), How Gen Z will transform corporate workplace culture.

[10] Steve Robertson (2018), Generation Z Characteristics \& Traits That Explain the Way They Learn.

[11]Tara Wyborny (2017), Generation Z: Independent, Flexible, Tech-Savvy and Now Working for you. 
[12] Ryan Jenkins (2019), How Generation Z will transform the future Workplace.

[13] Marianne Calnan (2017), Generation Z 'more motivated by teamwork than the average worker.

[14] Jack Jonson (2019), Gen Z Team Building: The \#FutureofWork for the post-digital generation.

[15]Erik (2020), Team Building in the Post-Digital Generation.

[16] Kolnhofer-Derecskei, A., Reicher, R. Z., \& Szeghegyi, A. (2017). The $X$ and Y generations' characteristics comparison. Acta Polytechnica Hungarica, 14(8), 107125.

[17] Wellner, A.S. (2000). Generation Z. American Demographics, 22 (9), 60-65.

[18] Langford, P. (2008). Gen Y or Boomer, They Think the Same. The Advertiser, 1, December 6, 36.

[19]Patel, D. (2017). 8 Ways Generation Z Will Differ From Millennials In The Workplace. Forbes

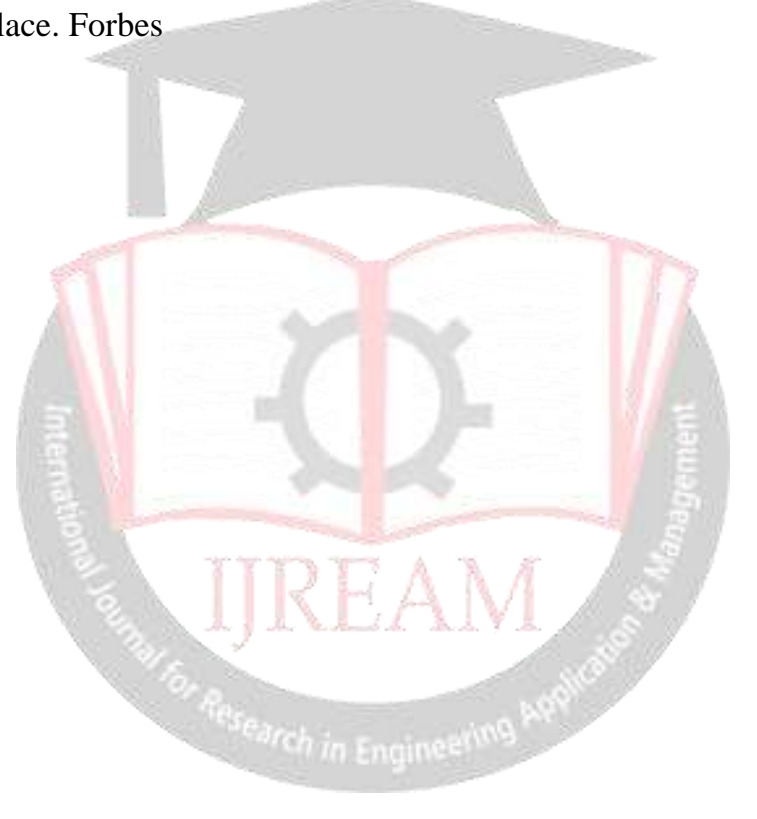

